\title{
Effect of Pretreatment and Drying Methods on the Quality of Anchote (Coccinia abyssinica (Lam.)) Flour
}

\author{
Abebe Desalegn ${ }^{1}{ }^{1}$ and Gesessew Kibr $\mathbb{D D}^{2}$ \\ ${ }^{1}$ Department of Chemical Engineering, Faculty of Technology, Shambu Campus, Wollega University, Shambu, Ethiopia \\ ${ }^{2}$ Department of Food and Nutritional Sciences, Faculty of Agriculture, Shambu Campus, Wollega University, Shambu, Ethiopia \\ Correspondence should be addressed to Abebe Desalegn; suabebe25@gmail.com
}

Received 11 July 2021; Accepted 1 November 2021; Published 16 November 2021

Academic Editor: Tatsadjieu Ngouné Léopold

Copyright (c) 2021 Abebe Desalegn and Gesessew Kibr. This is an open access article distributed under the Creative Commons Attribution License, which permits unrestricted use, distribution, and reproduction in any medium, provided the original work is properly cited.

\begin{abstract}
Reduction of postharvest losses through improved technique is studied in this work. Pretreatment and drying, in particular, are important methods for using various tuber-based food items to produce intermediate products that increase economic benefit and availability with a longer shelf life in the production and consumption communities. This study was conducted to evaluate the effect of pretreatment and drying methods on the proximate composition and physical and functional properties of flour developed from anchote. The treated anchote flour was prepared using hot distilled water for blanching and potassium metabisulphite solution and drying methods (sun, solar, and oven). The obtained data were statistically analyzed using SAS software at $P<0.05$. Accordingly, the untreated and sun-dried anchote had greater moisture content $(10.34 \%)$ than the chemically treated and oven-dried anchote $(8.71 \%)$. The samples treated with potassium metabisulphite and the solar-drying methods have higher protein content (4.02\%) than the blanched and sun-dried samples (3.14\%). Samples treated with blanching and solar drying have lower ash content (3.96\%) than samples treated with potassium metabisulphite and dried (4.89\%). The highest fiber content was recorded for samples treated with blanching and oven-drying methods, with a rating of $4.71 \%$. Sun-dried samples had an increased fat content $(1.14 \%)$ compared to blanch with all drying methods $(0.72 \%)$. The untreated and sun-dried flour had lower carbohydrate content $(80.95 \%)$ than blanched and oven-dried $(83.03 \%)$. The potassium-metabisulphite-treated and oven-dried samples rated $2.66 \%$ with the highest water absorption value. The blanched and oven-dried samples had the lowest oil absorption capacity of $1.71 \%$, a significantly different value from the highest value of $1.98 \%$ for the potassium-metabisulphite-treated and solar-dried samples. Oven-dried samples had higher swelling power than solar- and sun-drying methods. The anchote samples treated by blanching methods and dried in the oven had the highest solubility rating of $43.84 \%$ and the lowest value of $38.8 \%$ for control and sun-dried samples. The sun-dried anchote flour had the highest dispersibility value, which is significantly different from both the oven-dried and solar-dried versions. Along with that, the untreated samples had significantly lower dispersibility values than the potassium-metabisulphite-treated and blanched flour samples. The proximate values of anchote flour were significantly affected by pretreatment and drying methods. Additionally, the main and interactive effect of pretreatment and drying methods influenced the water absorption capacity, oil absorption capacity, swelling power, solubility, and dispersibility significantly. Further research is required to improve flour properties and characterize pasting properties to assess the suitability of the starch for different industrial inputs.
\end{abstract}

\section{Introduction}

Anchote (Coccinia abyssinica (Lam.) Cogn.) is a spherical- to cone-shaped indigenous tuber crop cultivated for human consumption in the southwestern areas of Ethiopia. It was among the Cucurbitaceae family and the Coccinia genus that were found in Ethiopia [1, 2]. For this reason, the raw anchote tuber had high moisture content [3]. Once harvested, it deteriorated rapidly. As a result, growers prefer to convert the tubers into more stable flour to prolong the shelf life of the product throughout the year $[4,5]$. Flour-related products are mostly the staple diet of most countries; hence, 
the availability of flour has often been a major economic issue [6]. However, during preserving anchote tuber, several drawbacks have been overlooked, such as discoloration, nutritional losses, and sensorial losses responsible for quality changes $[7,8]$.

Pretreatments were applied to stop the metabolism of wounded tissue, and they can be classified into two groups: chemical (sulfating, citric acid, and salt treatments) and nonchemical treatments (hot distilled water blanching, freezing, and osmotic pretreatment) [9]. Blanching is a unit operation before freezing, canning, or drying in which they are heated to inactivate enzymes, modify texture, preserve color, flavor, and nutritional value, and remove trapped air. Blanching helps to inactivate enzymes that may lead to quality degradation and improve the acceptability of the final product [10]. The author reported that blanching and dipping in sodium metabisulphite solution of yam can reduce the deterioration rate throughout processing and improve the acceptability of flour [11].

Besides pretreatment methods, different drying methods also affect the biochemical and functional properties of dehydrated products [12]. Food drying is a traditional method of food preservation, which is carried out for two main reasons, firstly to reduce the water activity which eventually increases the shelf life of food and next to reduce the weight and bulk of food for cheaper transport and storage. The development of drying technologies has been important for food and agroproducts such as tuber crops. At present, there are many drying techniques used for producing powder forms in the food industry; therefore, a suitable drying method for a particular food should be carefully selected. Many factors, such as the characteristics of the food material to be dried, the quality of the desired final product, and processing costs, that is, energy and space requirements, must be considered [13]. Drying methods can be broadly classified into solar drying and mechanical drying. Natural sun drying is practiced widely throughout the world and also in Ethiopia, but it has some problems related to contamination with dirt and dust and infestation by insects, rodents, and other animals [14]. Therefore, the convective drying process carried out on closed equipment is preferred [15].

Previous studies by Habtamu et al. [8] produced flour from raw anchote tubes through the process of boiling to characterize the anchote flour quality. In another study, Demelash [16] developed bread from anchote flour through the blanching method without using chemical treatment or different drying methods. Similarly, Melese et al. [17] developed cookies from anchote flour. Furthermore, Bikila et al. [18] investigated the effect of pretreatment methods (blanching and boiling) and drying at different temperatures on the quality of anchote flour. However, there was a gap in comparing and determining the effect of pretreatment methods and drying methods on the quality of anchote flour. This study was initiated to determine the effect of different pretreatment and drying methods on the proximate composition, physical properties, and functional properties of anchote flour. Thus, this study answers appropriate processing conditions for obtaining high-quality stable anchote flours.

\section{Materials and Methods}

2.1. Experimental Site. The experiment was conducted at Wollega University, Addis Ababa Science and Technology, and Jimma University. Drying anchote tuber and analysis of the proximate composition and physical and functional properties were carried out.

2.2. Sample Collection and Preparation. Anchote Coccinia abyssinica (Lam.) was obtained from the Nekemte within 24 hours of harvest. Nekemte Town is the capital city of eastern Wollega, Ethiopia, located $335 \mathrm{~km}$ west of Addis Ababa, at $9^{\circ} 04^{\prime}$ north latitude and $38^{\circ} 30^{\prime}$ east longitude, with an altitude of 1960 to $2170 \mathrm{~m}$ above sea level. The samples were packed in polyethylene bags, kept in an icebox, and transported to the experimental site. Once in the laboratory, samples were mixed for composite analysis of the study variables and washed by clean tape water altogether to remove sand, dirt, and other adhering materials. The anchote tubers were grouped into lots (pretreatment, drying, and control) and then peeled and sliced to a uniform thickness of $5 \mathrm{~mm}$ using a Jagson slicer (Food slicer, JAG0100089, California), but length, width, and maturity aspects of the anchote were not determined constantly. The sliced anchote was blanched at $70^{\circ} \mathrm{C}$ for 3 minutes in a water bath (GLC 400, Grant Instruments, England) to inactivate enzymes that cause the browning reaction. About $0.2 \mathrm{~N}$ of potassium metabisulphite was used for chemical treatment for 10 minutes and draining. The pretreated (blanched at $70^{\circ} \mathrm{C}$, chemically treated) and controlled anchote sample portion was used for the preparation of anchote flour samples using different drying methods such as sun drying, solar drying, and oven drying. Each sliced anchote sample tuber was divided into three portions for drying. One portion was dried in the sun for 6 days (approximately 60 hours) at a temperature ranging from 27 to $33^{\circ} \mathrm{C}$ depending on the time of day, until the tubers were dried to a constant weight, while the other portion was dried using solar dryers for 5 days at a temperature ranging from 35 to $38^{\circ} \mathrm{C}$ depending on the time of day, until the tubers were dried to a constant weight. Another portion of anchote samples was oven-dried in a convective oven dryer operated at $70^{\circ} \mathrm{C}$ with a constant air velocity until the anchote tuber dried to constant weight. Each dried sample was milled into a fine powder using an electric grinder (NIMA model NM8300 Burman, Germany) until it passed through a $500 \mu \mathrm{m}$ sieve mesh size and finally packed separately in airtight cellophane bags to minimize heat build-up, kept in an icebox, and transported and sorted in the desiccator (Figure 1). Finally, nutritional analysis, physical parameters, and functional properties of flour were determined using their respective well-established methods.

2.3. Experimental Design. The experimental design used was a completely randomized design (CRD) for chemical composition, physical properties, and functional properties of anchote. The treatments were run in three replications (Table 1). 


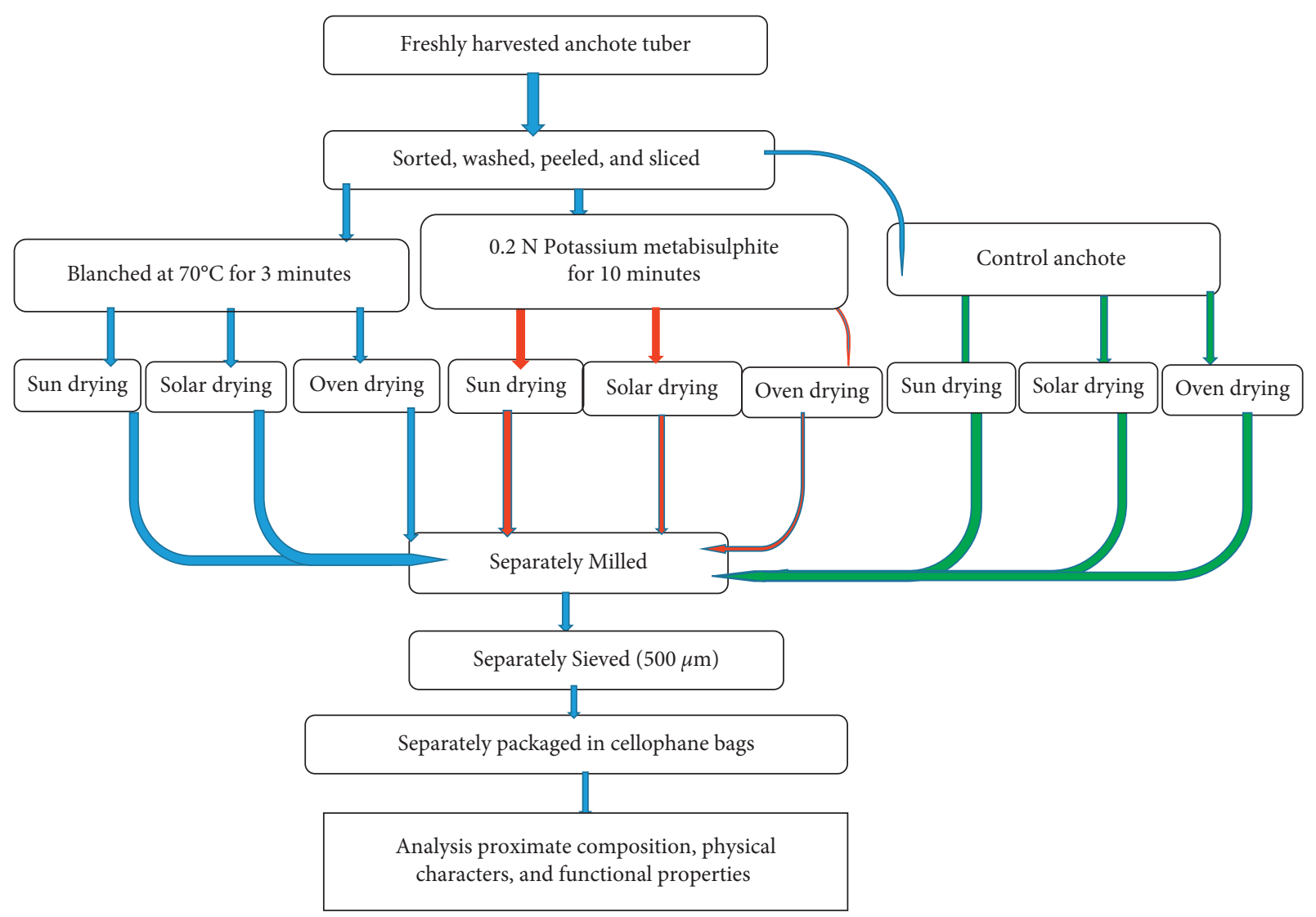

FIgURE 1: Anchote flour preparation and experimental design framework.

TABLE 1: Experimental layout.

\begin{tabular}{lccc}
\hline Factor 1 (pretreatment methods) & \multicolumn{3}{c}{ Factor 2 (drying methods) } \\
& S & So & C \\
\hline C & CS & CSo & BSo \\
B & BS & BO \\
K & KS & KSo & KO \\
\hline
\end{tabular}

C: control (untreated) anchote flour, S: sun-drying method, B: blanching anchote flour, So: solar-drying method, K: potassium-metabisulphite-treated anchote flour, and O: oven-drying method.

\subsection{Determination of Proximate Analysis of Anchote Flour}

2.4.1. Moisture Content. The moisture content was determined using dry method procedures described by the Association of Official Analytical Chemists (AOAC, 2000 method no. 925.10) [19]. The moisture content of each sample was determined by weighing $5 \mathrm{~g}$ of the sample into an aluminum moisture can. The sample was then dried to a constant weight at $105 \pm 2^{\circ} \mathrm{C}$ or 6 hours.

$$
\text { moisture content }=\frac{(\text { weight of initial sample }- \text { weight of dried sample })}{\text { weight of initial sample }} \times 100
$$

2.4.2. Crude Protein Content. The Kjeldahl method of nitrogen analysis was used during the determination of crude protein AOAC [19] as follows. All nitrogen was converted to ammonia by digestion with a mixture of concentrated sulfuric acid and concentrated orthophosphoric acid containing potassium sulfate as a boiling point raising agent and selenium as a catalyst. The ammonia released after alkalinization with sodium hydroxide was steam distilled into boric acid and titrated with sulfuric acid: $\mathrm{mg}$ nitrogen $\times 100 \mathrm{mg}$ sample mg nitrogen $=(T-B) \times N \times 14 \times 100$ 


$$
\begin{aligned}
\frac{\text { g nitrogen }}{100 \text { g sample }} & =\frac{\text { mg nitrogen } \times 100}{\text { mg of sample }}, \\
\text { total nitrogen }(\%) & =\frac{(T-B) \times N \times 14 \times 100}{W}, \\
\text { protein } & =\text { total nitrogen } \times 6.25,
\end{aligned}
$$

where $B=$ volume sulfuric acid solution used in titration for blank, $N=$ normality of acid, $14=$ equivalent weight of nitrogen, $W=$ weight of the sample, and $T=$ volume of sulfuric acid solution used in the titration of test materials.
2.4.3. Crude Fat Content. Crude fat was extracted in a Soxhlet extractor with hexane. The sample (1 g) was weighed into an extraction thimble and then stopped with grease-free cotton. Before extraction, the round bottom cans were dried, cooled, and weighed. The thimble is then placed in an extraction chamber and $80 \mathrm{ml}$ of hexane is added to extract the fat. The extraction was then carried out at $155^{\circ} \mathrm{C}$ lasting for 1 hour 40 minutes, after which the fat collected in the bottom cans was cooled in a desiccator.

$$
\text { crude fat }=\frac{\text { weight of }(\text { can }+ \text { fat })-\text { weight of empty can }}{\text { weight of sample }} \times 100 \text {. }
$$

2.4.4. Crude Fiber Content. Crude fiber analysis was conducted using the method of AOAC [19] official method 962.09. About $1.6 \mathrm{~g}$ weighted sample was transferred into a $600 \mathrm{ml}$ beaker and about $200 \mathrm{ml}$ of $1.25 \%$ sulfuric acid was added and boiled for 30 minutes. Recording took place by placing a watch glass over the mouth of the beaker. After 30 minutes of heating by gently keeping the level constant with distilled water, $20 \mathrm{ml} 28 \%$ potassium hydroxide was added and boiled gently again for another 30 minutes. Subsequently, washing was conducted with $1 \%$ sulfuric acid and sodium hydroxide solution. After filtering, it was dried in an electric oven at $130^{\circ} \mathrm{C}$ for 2 hours. Furthermore, it was cooled at room temperature for 30 minutes in a desiccator and was weighed; then, the crucibles were transferred to a muffle furnace for 30 minutes of ashing at $550^{\circ} \mathrm{C}$. Finally, it was cooled again in desiccators and reweighed. The crude fiber content was determined by using the formula:

$$
\text { crude fiber }(\%)=\left[\frac{M_{3}-M_{2}}{M_{1}}\right] * 100,
$$

where $M_{1}$ is the initial weight of samples, $M_{2}$ is the weight of the crucible, and $M_{3}$ is the weight of the crucible and dried sample.

2.4.5. Total Ash Content. The total ash content of the samples was determined by the method of the AOAC [19], using the official method 923.03. The porcelain crucible was cleaned, dried at $120^{\circ} \mathrm{C}$ in an oven, then ignited at about $550^{\circ} \mathrm{C}$ in a muffle furnace for 3 hours, cooled in desiccators, and weighed $\left(M_{1}\right)$. Then $2 \mathrm{~g}$ samples were weighed into a previously dried and weighed $\left(M_{2}\right)$ porcelain crucible. These samples were dried at $120^{\circ} \mathrm{C}$ for 1 hour and carbonized in an oven until the contents turned black. The crucible with the contents will be placed in a muffle furnace set at $550^{\circ} \mathrm{C}$ for 1 hour to ignite until the ashing is complete. After this period, the crucible with its content was removed and cooled in desiccators. The crucible with the residue was weighed $\left(M_{3}\right)$. The weight of the ash was expressed as a percentage of the initial weight of the samples. The total ash was expressed as percentages on a dry-matter basis as follows:

$$
\operatorname{total} \operatorname{ash}(\%)=\left[\frac{M_{3}-M_{1}}{M_{2}-M_{1}}\right] * 100
$$

where $M_{1}$ is the mass of the crucible $(\mathrm{g}), M_{2}$ is the mass of the crucible and the sample $(\mathrm{g}), M_{3}$ is the mass of the crucible and dried sample $(\mathrm{g})$, and $\left(M_{2}-M_{1}\right)$ is the initial sample weight $(\mathrm{g})$.

2.4.6. Carbohydrates. The total carbohydrate content of the anchote sample (\%) by mass can be obtained as follows:

$$
C \%=100-(P+F+A+M),
$$

where $P$ is the mass percent of protein, $F$ is the mass percent of fat, $A$ is the mass percent of ash, and $M$ is moisture content (\%). Therefore, the utilizable carbohydrate $(\mathrm{CHO})=$ total $\mathrm{CHO}-$ crude fiber.

\subsection{Determination of Physical Properties}

2.5.1. Bulk Density. The bulk density of the anchote flour samples was determined according to the method of Giambi et al. [20]; five grams of the sample was weighed into a $50 \mathrm{ml}$ graduated measuring cylinder. The sample was gently packed by tapping the cylinder on the benchtop 10 times from a height of $5 \mathrm{~cm}$. The volume of the sample was recorded and bulk density was calculated:

$$
\text { bulk density }(\mathrm{g} / \mathrm{ml})=\frac{\text { weight of flour used }}{\text { volume of the flour after tapping }} \text {. }
$$

2.5.2. Angle of Repose. The angle of repose was the angle formed by the horizontal base of a pile of flour and the inclined surface of a cone-like pile of flour. Anchote flour was placed over a plain surface and a cylinder was placed over that. Tapping during filling was done to obtain uniform packing and to minimize the wall effect if any. The cylinder tube was slowly lifted off the surface and the floor slid down, forming a cone-shaped heap. The height of the peak heap 
above the surface and the diameter of the heap at its base were measured and the angle of repose $(\varphi)$ was calculated by the following relations [21]:

$$
\text { the angle of repose }\left(\phi^{\circ}\right)=\tan ^{-1}\left(\frac{2 h}{d}\right) \text {, }
$$

where $\Phi$ is the angle of repose $\left(^{\circ}\right), h$ is the height of the heap $(\mathrm{mm})$, and $d$ is the diameter of the base of the heap $(\mathrm{mm})$.

2.5.3. Color. The color values of flour were measured in three different zones of the crust using a digital spectrophotometer Mini Scan EZ (Model: Cr-10 Minolta, Japan), which was provided with the software. A chronometer was calibrated with the standard black and white color. The results reported are averages of three measurements in each sample using CIELAB $L^{*}, a^{*}$, and $b^{*}$ values. The $L^{*}$ value is the lightness variable, from 100 for perfect white to zero for black, while $a^{*}$ and $b^{*}$ values are the chromaticity values, +redness/-greenness, and +yellowness/blueness, respectively [22]. The whiteness index (WI) for each sample was calculated according to the following equation [23]:

$$
\begin{aligned}
\operatorname{Chroma}\left(C^{*}\right) & =\sqrt{a^{* 2}+b^{* 2},} \\
\operatorname{Hue}\left(h^{*}\right) & =\tan ^{-1} \frac{b^{*}}{a^{*}} .
\end{aligned}
$$

\subsection{Determination of Functional Properties}

2.6.1. Water and Oil Absorption Capacity. The water absorption capacity of the flour samples was determined by comparison [24]. Two grams of the flour sample was preweighed into a centrifuge tube, $20 \mathrm{ml}$ of distilled water was added, and the tube containing the sample was carefully shaken by vortex and allowed to stand at room temperature $\left(25^{\circ} \mathrm{C}\right)$ for 30 minutes and it was centrifuged for 30 minutes. At $200 \mathrm{rpm}$, excess water was decanted by inverting the tube; the weight of the water was determined by the difference as follows:

$$
\text { water absorption capacity }(\mathrm{g} / \mathrm{g})=\frac{\left(W_{1}-\mathrm{W}_{2}\right)}{W_{S}} \times 100 \text {, }
$$

where $W_{1}$ is the weight of residue in the tube after using a centrifuge, $W_{2}$ is the weight of empty tube before using a centrifuge, and $W_{S}$ is the weight of the sample used.
Oil absorption ability was determined using the method of AOAC (2000) using the following formula:

$$
\text { oil absorption capacity }(\mathrm{g} / \mathrm{ml})=\frac{\left(V_{1}-V_{2}\right)}{W_{S}} \times 100,
$$

where $V_{1}$ is the volume of residue in the tube after centrifuge, $V_{2}$ is the volume of the empty tube before centrifuge, and $W_{S}$ is the weight of sample used.

2.6.2. Swelling Power and Solubility Index. Swelling power and solubility determination were carried out in the temperature range of $60-90^{\circ} \mathrm{C}$ using the method of Leach et al. [25]. A gram of anchote flour was precisely weighed and quantitatively transferred into a clear, dried test tube before being weighed. About $15 \mathrm{ml}$ of distilled water was added and mixed gently at a low speed for 5 minutes. The slurry was heated in a thermostatic water bath at $80^{\circ} \mathrm{C}$ for 30 minutes, mixing the suspension intermittently. The test tube's contents were rapidly cooled to $20^{\circ} \mathrm{C}$. During heating, the slurry was stirred gently to prevent lumps from forming in the flour. Then the cool paste was centrifuged at $2200 \mathrm{rpm}$ for 15 minutes. The supernatant was decanted immediately after centrifuging into a preweighed evaporating can and dried at $100^{\circ} \mathrm{C}$ to constant weight for approximately four hours. The weight of the sediment was taken and recorded as swollen mass.

$$
\begin{aligned}
& \text { swelling power }(\%)=\frac{\text { weight of sediment }}{\text { weight of sample }- \text { weight of soluble }}, \\
& \text { solubility index }(\%)=\frac{\text { weight soluble }}{\text { weight of sample }} \times 100 .
\end{aligned}
$$

2.6.3. Foaming Properties. The foam capacity (FC) was determined according to the method of Lawhon et al. [26]. A sample (3 g) was dispersed in $100 \mathrm{ml}$ of distilled water and $\mathrm{pH}$ adjusted to 7.0 using either $1 \mathrm{M}$ hydrochloric acid or sodium hydroxide. The contents were transferred to a mixer, blender whipped at high speed for 5 minutes. The content, along with the foam, was poured into a $250 \mathrm{ml}$ measuring cylinder and the foam volume was recorded after 30 seconds. FC was expressed as a percentage increase in volume. After 30 minutes, the volume of foam was measured and expressed as FC.

$$
\mathrm{FC}(\%)=\frac{\text { volume after homogenization }- \text { volume before homogenization }}{\text { volume before homogenization }} \times 100
$$


2.6.4. Dispersibility. Dispersibility was determined using AOAC (2000) and it was calculated by the means of the following formula by taking a $10 \mathrm{~g}$ sample using the $100 \mathrm{ml}$ measuring cylinder with water. Then, the volume of settled particles was recorded after vigorous stirring and allowing standing for three hours.

$$
\text { dispersibility }(\%)=100-\text { the volume of settled particles. }
$$

2.7. Data Analysis. Analysis of variance (ANOVA) was conducted by a factorial test in a complete randomized design with three replicates in pretreatments and drying method, to evaluate the individual effect of independent variables on the effective chemical composition, functional properties, and physical properties of anchote. All the data were analyzed using the statistical analysis software (SAS) 9.1 package (SAS Institute Inc., Cary, NC). The mean comparisons were drawn using Fisher's protected least significant difference (LSD) at a probability level of $5 \%$.

\section{Results and Discussion}

\subsection{Proximate Composition of Anchote Flour}

3.1.1. Moisture Content. The moisture content results for pretreated and dried anchote are presented in Table 2 . The moisture content was significantly $(P<0.05)$ affected by the pretreatment, drying methods, and their interaction. The untreated (control) anchote dried under the open sun had a greater moisture content of $10.34 \%$, which is significantly different $(P<0.05)$ from the lowest values of $8.71 \%$ for the anchote samples chemically treated and dried in the oven dryer. This very low value of moisture content for chemically treated foods might be due to the ability of potassium metabisulphite to cause dehydration in anchote slices. Additionally, oven-dried anchote flours recorded the lowest moisture content. The same study was reported by Gbemisola et al. [27] from the plantain flour samples dried under the sun, solar dryer, and oven; the oven-dried samples scored the lowest moisture value. This might be due to the high temperature applied for a moderately short time compared to the sun and solar dryer. The moisture content of anchote flour ranged from 8.71 to $10.34 \%$. Other authors $[16,18]$ reported comparable moisture content for anchote flour of 7.1-10.40 g/100 g and 9.78\%. However, all the anchote flour samples had the moisture content within a favorable range for effective storage of the flour with minimal risk of microbial contamination. The moisture content of flours below $14 \%$ is capable of resisting microbial growth, resulting in shelf-stable flour [28].

3.1.2. Crude Protein Content. According to Table 2, pretreatment, drying methods, and their interactions had a significant $(P<0.05)$ effect on protein content. The value of anchote flour ranged from 3.14 to $4.02 \%$. This study result was in the range of $2.67-3.25 \%$ and $3.25-4.80 \%$ reported by Habtamu et al. [29] and Bikila et al. [18], respectively, for anchote flour, but lower than that (10.7\%-13.72\%) reported by Yenenesh et al. [30]. The blanched and sun-dried samples recorded the lowest crude protein content of $3.14 \%$, with a significant $(P<0.05)$ difference from the others, and the highest $4.02 \%$ value was for potassium-metabisulphitetreated and solar-dried anchote flour samples. The protein content of the potassium-metabisulphite-treated samples is significantly $(P<0.05)$ higher than that of the control and blanched samples. The lowest protein content was noticed for blanched anchote due to blanching causing leaching losses of nitrogen particles from anchote during treatments [31]. Similarly, the drying method also had a significant $(P<0.05)$ effect on the crude protein content of the anchote samples. From those drying techniques, solar-dried samples have more protein content with significant differences $(P<0.05)$ from both samples dried under the oven and in the sun. On the other hand, sun-dried samples resulted in reduced crude protein content due to protein denaturation and prolonged drying, whereby the same reason was reported by different researchers [32].

3.1.3. Total Ash Content. Ash is the inorganic residue produced after the organic matter in a foodstuff is ignited or completely oxidized. The ash content values of the anchote sample ranged from 3.96 to $4.89 \%$, and the comparable ash value $2.96-4.74 \%$ was reported for anchote flour [18]. Nevertheless, it contradicts with the report by Habtamu et al. [29], 1.33-2.19\%. The ash content was significantly $(P<0.05)$ affected by the pretreatment method, the drying method, and the interaction between the pretreatment and the drying method, as shown in Table 2. The pretreatment method was a more dominantly significant factor than that of the drying methods. However, the samples treated with blanching and solar-drying methods had the lowest value of $3.96 \%$, and the highest value was for samples treated with potassium metabisulphite and dried with a sun rating of $4.89 \%$ with a significant difference between them. The highest value for chemically treated samples might be due to the diffusion of solutes from potassium metabisulphite solution to anchote samples during soaking. Ahmed et al. [7] observed similar results of an ash content increase in pretreated sweet potato flour while treating the sample chemically. The blanched anchote records the lowest value of ash content due to the movement of material from treated samples to the hot water through leaching. The same trend was reported by Fana et al. [33]; the samples treated with blanching had the lowest ash content compared to those of untreated or chemically treated sweet potato samples.

3.1.4. Crude Fiber Content. The food fibers are defined as the sum of nonstarchy polysaccharides and lignin, which are the main components of plant cell walls. The fiber content value was measured from 3.22 to 4.71 for all pretreated and dried samples. This study was analogous with the author's report for fiber content $2.58-3.71 \%$ [8] but less than the range of 7.24-10.16\% [18]. According to the data in Table 2, pretreatments, drying methods, and the interaction effects of pretreatments and drying methods have been shown to have 
TABle 2: Proximate composition of anchote flour as affected by pretreatments and drying methods.

\begin{tabular}{lcccccc}
\hline Dr $*$ Prt & Moisture (\%) & Protein (\%) & Ash (\%) & Fiber (\%) & Fat $(\%)$ & Carbohydrate $(\%)$ \\
\hline CS & $10.34 \pm 0.06^{\mathrm{a}}$ & $3.27 \pm 0.02^{\mathrm{de}}$ & $4.87 \pm 0.05^{\mathrm{a}}$ & $3.22 \pm 0.61^{\mathrm{e}}$ & $1.01 \pm 0.41^{\mathrm{b}}$ & $80.95 \pm 0.43^{\mathrm{d}}$ \\
CSo & $9.62 \pm 0.19^{\mathrm{c}}$ & $3.33 \pm 0.05^{\mathrm{d}}$ & $4.83 \pm 0.03^{\mathrm{b}}$ & $3.63 \pm 0.02^{\mathrm{d}}$ & $1.14 \pm 0.03^{\mathrm{a}}$ & $81.92 \pm 0.01^{\mathrm{c}}$ \\
CO & $9.04 \pm 0.14^{\mathrm{de}}$ & $3.33 \pm 0.07^{\mathrm{d}}$ & $4.79 \pm 0.01^{\mathrm{c}}$ & $3.84 \pm 0.03^{\mathrm{c}}$ & $0.91 \pm 0.05^{\mathrm{d}}$ & $82.37 \pm 0.05^{\mathrm{b}}$ \\
BS & $9.92 \pm 0.31^{\mathrm{b}}$ & $3.14 \pm 0.05^{\mathrm{f}}$ & $3.98 \pm 0.02^{\mathrm{d}}$ & $3.92 \pm 0.01^{\mathrm{c}}$ & $0.83 \pm 0.05^{\mathrm{f}}$ & $81.95 \pm 0.02^{\mathrm{c}}$ \\
BSo & $9.14 \pm 0.15^{\mathrm{d}}$ & $3.22 \pm 0.61^{\mathrm{ef}}$ & $3.96 \pm 0.01^{\mathrm{d}}$ & $4.32 \pm 0.12^{\mathrm{b}}$ & $0.92 \pm 0.31^{\mathrm{d}}$ & $82.33 \pm 0.06^{\mathrm{b}}$ \\
BO & $8.91 \pm 0.13^{\text {ef }}$ & $3.16 \pm 0.05^{\mathrm{f}}$ & $3.99 \pm 0.02^{\mathrm{d}}$ & $4.71 \pm 0.12^{\mathrm{a}}$ & $0.72 \pm 0.01^{\mathrm{h}}$ & $83.03 \pm 0.07^{\mathrm{a}}$ \\
KS & $9.16 \pm 0.02^{\mathrm{d}}$ & $3.86 \pm 0.04^{\mathrm{b}}$ & $4.89 \pm 0.02^{\mathrm{a}}$ & $3.57 \pm 0.02^{\mathrm{d}}$ & $0.88 \pm 0.05^{\mathrm{e}}$ & $81.72 \pm 0.01^{\mathrm{c}}$ \\
KSo & $8.87 \pm 0.05^{\mathrm{fg}}$ & $4.02 \pm 0.01^{\mathrm{a}}$ & $4.83 \pm 0.01^{\mathrm{b}}$ & $3.63 \pm 0.05^{\mathrm{d}}$ & $0.98 \pm 0.05^{\mathrm{c}}$ & $81.87 \pm 0.01^{\mathrm{c}}$ \\
KO & $8.71 \pm 1.13^{\mathrm{g}}$ & $3.76 \pm 0.09^{\mathrm{c}}$ & $4.82 \pm 0.02^{\mathrm{bc}}$ & $3.90 \pm 0.01^{\mathrm{c}}$ & $0.77 \pm 0.01^{\mathrm{g}}$ & $81.92 \pm 0.81^{\mathrm{c}}$ \\
LSD & 0.16 & 0.5 & 0.03 & 0.10 & 0.02 & 0.25 \\
CV & 1.02 & 1.44 & 2.39 & 1.52 & 1.50 & 2.17 \\
\hline
\end{tabular}

Values are mean \pm standard deviation. Values in the same column followed by different letters are significantly different $(P<0.05)$. CS: control and sun-dried sample, CSo: control and solar-dried sample, CO: control and oven-dried sample, BS: blanching and sun-dried sample, BSo: blanching and solar-dried sample, BO: blanching and oven-dried sample, KS: potassium metabisulphite and sun-dried sample, KSo: potassium metabisulphite and solar-dried sample, KO: potassium metabisulphite and oven-dried sample, LSD: least significant difference, and CV: coefficient of variation.

a significant $(P>0.05)$ difference in fiber content. The highest fiber content value was recorded for samples pretreated with blanching methods and dried under an oven drier rating of $4.71 \%$, and the lowest fiber content was for control samples dried by the sun at $3.22 \%$, with a significant $(P>0.05)$ difference between them.

These increases in fiber content under the blanching method might be because the raw anchote was subjected to hot water, and thus all soluble components might have been lost in the process, thereby increasing the crude fiber content [8]. Similarly, another study also suggested that blanching and boiling anchote might enhance the loss of water-soluble components and increase the percentage of macromolecules rich in dietary fiber [18]. The high fiber content found in this study may have a positive impact on the dietary fiber content of flours. Consumption of an ample quantity of dietary fiber decreases the risk of diseases such as obesity, constipation, gallstones, diabetes, and coronary heart diseases [34]. This is an indication that the landraces and processing conditions are suitable for producing anchote flour advantageous to the health of consumers.

3.1.5. Fat Content. Fats are very necessary to the structure and biological functions of cells and are used as alternative energy sources. There was a significant difference $(P>0.05)$ between the fat content of samples due to the pretreatment method and drying methods and the interaction between the pretreatment method and drying methods as shown in Table 2. Still, both factors share equal effects on the fat contents of anchote. Knowingly, anchote is considered to be a low-fat food, between 0.13 and $0.19 \%$, depending on the cultivar [8]. Corroborating this statement, this study determined fat content values ranging from 0.72 to $1.14 \%$. The fat content of the control and sun-dried samples is higher, whereas the fat content of the blanched samples decreased with all drying methods. The study supported that sun-dried root and tuber crops had higher fat than other drying methods [31]. The reduction of fat content in the blanched anchote samples might be due to oxidation as temperature increases [33]. The low content of fat will enhance the storage life of the food products due to the lowered chance of rancid flavor development [35]. The same trend was reported by Fan et al. [33]; the orange-fleshed sweet potato flour treated with sun drying had higher fat content than other samples dried under different drying methods with various pretreatment methods.

3.1.6. Carbohydrate Content. The carbohydrate contents of anchote samples were significantly $(P>0.05)$ affected by the pretreatments and drying methods, and their interaction is shown in Table 2. The untreated (control) and sun-dried anchote flour had the lowest carbohydrate content rating of $80.95 \%$, whilst the blanched and oven-dried samples had the highest carbohydrate content rating of $83.03 \%$ with a significant $(P>0.05)$ difference. The oven-dried anchote flour resulted in higher carbohydrate content than other drying methods. This study supports the fact that regular and high application of heat increases the carbohydrate content of the plantain flour more than sun-dried plantain flour [27]. Although the same pattern was shown by another study by Fana et al. [33], the blanched and fluidized bed dried sweet potatoes had higher carbohydrate content than other drying methods, with a value ranging from 80.01 to $84.2 \%$. Generally, tuber crops are a high source of carbohydrates. According to this study, anchote was one type of crop containing a carbohydrate content ranging from 80.01 to $83.66 \%$ for anchote [18], 77.33 to $82.51 \%$ [35] for cassava flour, 74.55 to $90.92 \%$ [36] for sweet potato, and 84.56 to $86.80 \%$ [37] for potato.

\subsection{Physical Properties of Anchote Flour}

3.2.1. Bulk Density. Bulk density reveals the comparison of weight and volume, which influences package design and could be used in determining the type of packaging material required [38]. The bulk density result was significantly $(P<0.05)$ affected by the pretreatment methods and the drying methods. The interaction of the pretreatment and drying methods had no significant $(P<0.05)$ influence, as shown in Figure 2. The bulk density of anchote flour ranges from 0.71 to $0.76 \mathrm{~g} / \mathrm{ml}$, categorized under higher bulk density 


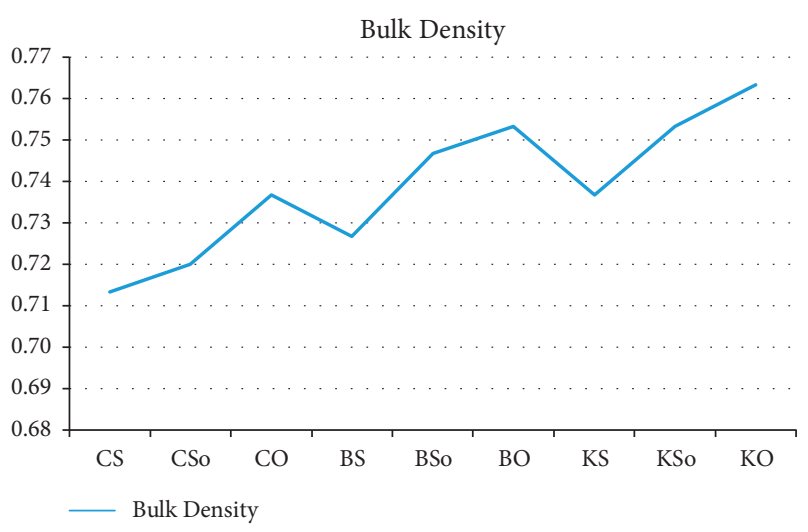

FIGURE 2: Bulk density of anchote flours. CS: control and sun-dried sample, CSo: control and solar-dried sample, CO: control and oven-dried sample, BS: blanching and sun-dried sample, BSo: blanching and solar-dried sample, BO: blanching-oven-dried sample, KS: potassium metabisulphite and sun-dried sample, KSo: potassium metabisulphite and solar-dried sample, and KO: potassium metabisulphite and oven-dried sample.

flours [39]. These values were comparable to the findings of other researches, $0.71-0.83 \mathrm{~g} / \mathrm{ml}$ and $0.82 \mathrm{~g} / \mathrm{ml}[17,18]$, respectively. The untreated anchote flour had a significantly lower bulk density than the treated anchote flour. However, there is no significant $(P<0.05)$ difference between blanched and potassium-metabisulphite-treated anchote samples. Moreover, blanching could increase the bulk density of anchote flour samples. This study was supported by Balagopalan et al. [40]; blanching confers a harder consistency to chips due to the gelatinization of starch. This, ultimately, toughened the chips, leading to the production of granulated materials, which had a higher bulk density than unblanched flour. Additionally, the variation of bulk density values was due to the particle size and initial moisture content of flours [41].

As shown in Figure 2, the bulk density value increased as the temperature value increased. Similarly, pretreating the anchote flour increases the bulk density more than the control. The lowest bulk density value was observed for control anchote samples and dried by sun rating at $0.71 \mathrm{~g} / \mathrm{ml}$, and the highest value, $0.76 \mathrm{~g} / \mathrm{ml}$, was noticed for potassiummetabisulphite-treated and oven-dried samples with a significant difference between them among all treatments. According to Fadimu et al. [42], the same pattern was indicated for the bulk density of plantain flour. The value ranged from 0.68 to $0.70 \mathrm{~g} / \mathrm{ml}$ with the oven, cabinet, and solar-dried samples having higher bulk density than the sundried. High bulk density is a desirable property in flour. For instance, the bulk density of sweet potato flour is $0.745 \mathrm{~g} / \mathrm{ml}$, which can be used as a thickener or base in foods such as yogurt [39]. This suggests that all anchote flours could be used as a thickener in the food industry to give food products a body and mouthfeel. The high bulk density of flour material is important in its packaging. It is desirable to have a high bulk density in that it offers a greater packaging advantage, as a greater quantity may be packed into a constant volume [43].
3.2.2. Angle Repose. The angle of repose of the anchote samples ranged from 30.71 to $34.02^{\circ}$ as shown in Figure 3 . These studies support the anchote flour angle of repose values of $31.23^{\circ}$ with very good flow reported by Melese et al. [18], but it is lower than the commercial rice flour angle of repose of $66.57^{\circ}$, which has very poor inflow [21]. The drying method significantly $(P<0.05)$ affects the angle of repose of the anchote flour samples. However, the pretreatment methods and the combined effect of pretreatment and drying methods had no significant $(P>0.05)$ effect on the angle of repose of anchote flour samples. The control and sun-dried anchote flour recorded the highest angle of repose rating of $34.02^{\circ}$ whilst the blanched and oven-dried samples had the lowest value rating of $30.71^{\circ}$ with a significant difference between them. This was due to the highest moisture content of sun-dried flour, resulting in an increasing pattern of the angle of repose in samples dried at lower drying temperatures, as samples dried at lower temperatures tend to contain more moisture and the surface layer of moisture surrounding the particles holds them together by surface tension [44].

3.2.3. Color. The pretreatment methods, drying methods, and the interaction between pretreatment and drying methods could significantly affect $(P<0.05)$ the $L^{*}$ values of anchote flour samples as shown in Table 3 . The whiteness value was in the range of 75.48-84.29. The analogous result was noticed for anchote flour $L^{*}$ value 82.24 [45], but lower than the $L^{*}$ values of cassava flour 81.86-90.89 [46], for sweet potato 79.90-101.48 [36], and commercial wheat flour 92.5 [19]. The untreated samples and those dried under the sun had the lowest value rating of 75.48 , and the potassiummetabisulphite-treated flour and solar-dried samples had the highest value rating of 84.29 , with a significant $(P<0.05)$ difference between them.

The highest whiteness index was observed in this study for potassium-metabisulphite-treated anchote flour; this might be due to the potential of the pretreatments to retard both enzymatic and nonenzymatic reactions in the anchote flour. Pretreatments such as sulfite and its salts are used to preserve the color of fruits and vegetables because of their ability to retard both enzymatic and nonenzymatic reactions [47]. From the drying techniques, solar-dried samples had a higher whiteness value than the oven and sun-dried samples with a significant $(P<0.05)$ difference for all samples. The lowest $L^{*}$ value for sun-dried samples may be due to prolonged drying time and the presence of oxygen [48]. $L^{*}$ is a crucial parameter for drying since it is typically the first quality attribute that is measured by consumers for the determination of brand acceptance [49].

The $a^{*}$ values varied significantly $(P<0.05)$ among the samples due to the pretreatment method, drying methods, and their interaction as shown in Table 3. The value of anchote flour ranged from 3.02 to 6.34. A similar result was reported, the $a^{*}$ value of 6.63 for anchote flour [45]. Regarding the analysis of the red/green color of the sample, the control and sun-dried anchote flour were measured at high ratings of 6.34 and $3.02 a^{*}$ values, with a significant 


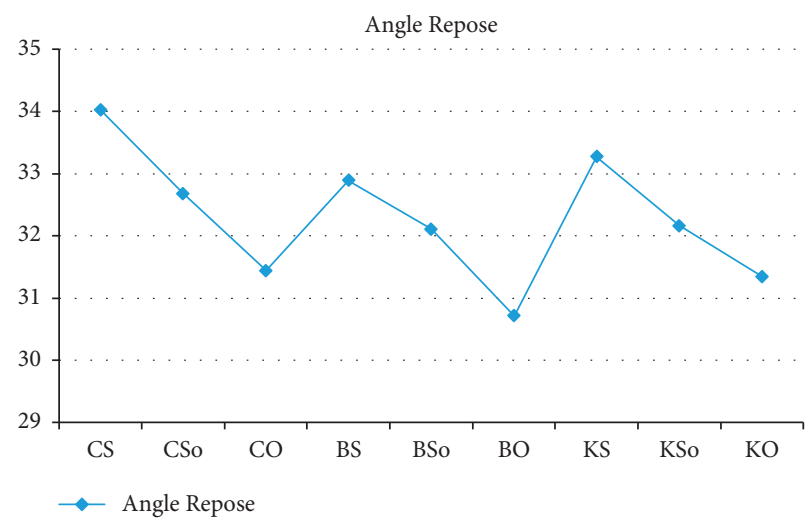

Figure 3: Angle repose of anchote flours. CS: control and sun-dried sample, CSo: control and solar-dried sample, CO: control and ovendried sample, BS: blanching and sun-dried sample, BSo: blanching and solar-dried sample, BO: blanching-oven-dried sample, KS: potassium metabisulphite and sun-dried sample, KSo: potassium metabisulphite and solar-dried sample, and KO: potassium metabisulphite and ovendried sample.

TABLE 3: Color properties of anchote flour as affected by pretreatments and drying methods.

\begin{tabular}{lccccc}
\hline Dr *Prt & $L^{*}$ & $a^{*}$ & $b^{*}$ & Hue $\left(^{\circ}\right)$ & Chrom $^{\mathrm{o}}$ \\
\hline CS & $75.48 \pm 0.66^{\mathrm{g}}$ & $6.34 \pm 0.31^{\mathrm{a}}$ & $17.48 \pm 0.32^{\mathrm{f}}$ & $70.05 \pm 0.79^{\mathrm{f}}$ & $18.60 \pm 0.36^{\mathrm{e}}$ \\
CSo & $78.81 \pm 0.29^{\mathrm{e}}$ & $4.18 \pm 0.11^{\mathrm{cd}}$ & $18.38 \pm 0.15^{\mathrm{e}}$ & $77.18 \pm 0.35^{\mathrm{d}}$ & $18.85 \pm 0.15^{\mathrm{de}}$ \\
CO & $76.90 \pm 0.78^{\mathrm{f}}$ & $5.41 \pm 0.21^{\mathrm{b}}$ & $18.66 \pm 0.31^{\mathrm{e}}$ & $73.82 \pm 0.45^{\mathrm{e}}$ & $19.43 \pm 0.34^{\mathrm{cd}}$ \\
BS & $79.71 \pm 0.46^{\mathrm{e}}$ & $4.41 \pm 0.1^{\circ} \mathrm{C}$ & $20.70 \pm 0.56^{\mathrm{bc}}$ & $77.95 \pm 0.67^{\mathrm{d}}$ & $21.16 \pm 0.53^{\mathrm{ab}}$ \\
BSo & $82.44 \pm 0.40^{\mathrm{bc}}$ & $3.79 \pm 0.19^{\mathrm{e}}$ & $21.27 \pm 0.67^{\mathrm{ab}}$ & $79.88 \pm 0.48^{\mathrm{a}}$ & $21.60 \pm 0.66^{\mathrm{a}}$ \\
BO & $81.93 \pm 0.54^{\mathrm{c}}$ & $4.02 \pm 0.09^{\mathrm{de}}$ & $21.43 \pm 0.25^{\mathrm{a}}$ & $79.37 \pm 0.36^{\mathrm{bc}}$ & $21.81 \pm 0.28^{\mathrm{a}}$ \\
KS & $80.83 \pm 0.46^{\mathrm{d}}$ & $4.36 \pm 0.18^{\mathrm{c}}$ & $19.51 \pm 0.27^{\mathrm{d}}$ & $77.40 \pm 0.37 \mathrm{~d}$ & $19.99 \pm 0.29^{\mathrm{c}}$ \\
KSo & $84.29 \pm 0.97^{\mathrm{a}}$ & $3.02 \pm 0.09^{\mathrm{f}}$ & $20.49 \pm 0.15^{\mathrm{c}}$ & $81.61 \pm 0.32 \mathrm{a}$ & $20.71 \pm 0.18^{\mathrm{b}}$ \\
KO & $83.09 \pm 0.17^{\mathrm{b}}$ & $3.79 \pm 0.18^{\mathrm{e}}$ & $19.45 \pm 0.37^{\mathrm{d}}$ & $78.95 \pm 0.65 \mathrm{c}$ & $19.82 \pm 0.35^{\mathrm{c}}$ \\
LSD & 1.05 & 0.31 & 0.68 & 0.86 & 0.68 \\
CV & 0.76 & 4.14 & 2.07 & 0.65 & 1.97 \\
\hline
\end{tabular}

Values are mean \pm standard deviation. Values in the same column followed by different letters are significantly different $(P<0.05)$. CS: control and sun-dried sample, CSo: control and solar-dried sample, CO: control and oven-dried sample, BS: blanching and sun-dried sample, BSo: blanching and solar-dried sample, BO: blanching and oven-dried sample, KS: potassium metabisulphite and sun-dried sample, KSo: potassium metabisulphite and solar-dried sample, KO: potassium metabisulphite and oven-dried sample, LSD: least significant difference, and CV: coefficient of variation.

$(P<0.05)$ difference. This study supports the pretreatment method. The unblanched potato sample has a higher $a^{*}$ value of 2.69 than that of the blanched samples, with a positive $a^{*}$ value of 1.24 [50]. Additionally, the drying methods also had a significant $(P<0.05)$ effect among the samples for $a^{*}$ color value. During drying, both enzymatic and nonenzymatic reactions cause the browning of fruits and vegetables [51]. The sun-dried anchote samples have the highest $a^{*}$ value, followed by the solar and oven-dried samples, which have a significant difference among them. This implies the sun dryer takes a prolonged time and direct contact with oxygen, which is responsible for increasing the reddish color of flour.

Table 3 reveals that the pretreatment method, drying methods, and the combination of the pretreatment and drying methods can significantly $(P<0.05)$ affect the $b^{*}$ values of anchote flour. The yellowness/blueness value of flours varied from 17.48 to 21.43. A comparable result was reported by Abebe and Demelash, $17.76 b^{*}$ value [45]. The treated samples before drying could have a higher yellowness value than control anchote samples. However, from pretreatment methods, the potassium metabisulphite treatment could decrease the yellowness values of anchote flour, whilst blanching could increase the yellowness value. Consequently, drying methods can also affect the yellowness values of anchote flour, as shown in Table 3. The open sun-dried anchote samples have lower yellowness values than both solar and oven-dried anchote samples.

The ${ }^{\circ}$ Hue angle has been described as the color perceived by the naked eye and is measured in degrees. According to this study, the values ranged from 70.05 to $81.61^{\circ}$ for hue angle and 18.6 to $21.81^{\circ}$ for chroma as shown in Table 3. A comparable result was reported with a hue angle of $69.55^{\circ}$ and chroma of $18.96^{\circ}$ for anchote flour [45]. Hue angles greater than $90^{\circ}$ denote a yellowish color, whereas those lower than $90^{\circ}$ suggest a slightly yellow to orange color [52]. The hue angle would have been significantly affected by the pretreatment methods, drying methods, and interaction of the pretreatment and drying methods. The potassiummetabisulphite-treated and solar-dried anchote flour had the highest value rating of $81.61^{\circ}$, while the lowest was for control and sun-dried anchote flour, with a significant $(P<0.05)$ difference between them. In this study, blanched, potassium metabisulphite, and solar-dried anchote samples 
were followed at the higher hue angle. The chroma value was significantly $(P<0.05)$ affected by the pretreatment methods, drying methods, and their interaction. The highest chroma value was recorded for blanched and oven-dried samples, and the lowest value was for the untreated and sundried anchote flour, with a significant $(P<0.05)$ difference between them.

3.3. Functional Properties of Anchote Flour. The functional properties of flour are those that directly determine their end uses. It has been established that the composition and nature of macromolecules (proteins, fat, and carbohydrates) in food materials often affect their functionality [53]. The data in Table 4 show that pretreatments and drying methods exhibit a significant effect on the water absorption of anchote flour. The interaction between pretreatment methods and drying methods significantly $(P<0.05)$ affects the water absorption capacity as displayed in Table 4 . The value of water absorption capacity ranged from 2.04 to $2.66 \%$, although a comparable result was reported by Melese et al. [17], a 2.44\% water absorption capacity of anchote flour. However, the lowest value was reported for sweet potato flour, ranging from 1.4 to $2.8 \%$ [36], and the highest value was reported for yam flour, at $4.47-5.75 \%$ [54]. The potassium-metabisulphite-treated and oven-dried anchote samples rated $2.66 \%$ of the highest water absorption values, whilst the control and sun-dried samples rated $2.04 \%$ of the lowest values, having a significant difference between the samples. The same pattern-finding method was reported by Fan et al. [33]. The chemically treated sweet potato and fluidized bed dried samples had higher values than other pretreatment methods.

The treated anchote samples have a higher water absorption capacity than untreated samples with a significant difference. The potassium-metabisulphite-treated anchote sample has a higher water absorption capacity than other methods. Similarly, in another study, Ngoma et al. [28] reported that the water absorption capacity of sweet potato flour pretreated with sodium metabisulphite and citric acid ranged from 1.63 to $2.03 \mathrm{ml} / \mathrm{g}$, which was a greater value than that of the control flour at $1.44 \mathrm{ml} / \mathrm{g}$.

According to this study, regular heat supply and high temperature (oven) drying could increase the water absorption capacity more than solar and sun-dried anchote flour. Other studies by Gbemisola et al. [27] support the fact that oven-dried plantain fruit samples have higher water absorption capacities than solar and sun-dried samples. Generally, blanching and potassium-metabisulphite-treated and dried-under-oven anchote flour samples had the highest water absorption capacity. This shows that anchote flour will retain large quantities of water during the preparation of food items such as gruels and thus become voluminous with low energy and nutrient density [55]. In the same way, flour with high water absorption capacity may be used in the production of some bakery products $[56,57]$. It will also be useful in food systems that need water to be prepared, such as meat sausages, bakery goods, dough, and processed cheese [28].
Oil absorption is the capacity of absorbing oil through a dynamic mechanism of capillary attraction [58]. The mechanism of fat absorption is attributed mainly to the physical entrapment of oil and the binding of fat to a polar chain of the protein [6]. The analysis revealed that the main effect, as well as the interactions of pretreatment and drying methods, had a significant difference $(P<0.05)$ on oil absorption capacity (Table 4$)$. The oil absorption capacity value ranged from 1.71 to $2.07 \mathrm{ml} / \mathrm{g}$. Similarly, the oil absorption capacity of anchote flour was $1.92 \mathrm{ml} / \mathrm{g}$ reported by Melese et al. [17] and 1.1 to $1.82 \mathrm{ml} / \mathrm{g}$ [8]. However, another author reported the highest oil absorption for yam flour with different species, pretreatment, and drying methods ranging from 7.53 to 7.96 [59]. The blanched and oven-dried samples had the lowest oil absorption capacity of $1.71 \mathrm{ml} / \mathrm{g}$, which was a significantly different value from the highest value of $2.07 \mathrm{ml} / \mathrm{g}$ for the potassium-metabisulphite-treated and solar-dried samples. The blanching treatment methods could significantly decrease the oil absorption capacity of the anchote flour; this may be due to oxidation which causes rancidity. However, the potassium-metabisulphite-treated and solar-drying methods are attributed to high oil absorption capacity, so they are important for producing consumable products such as cakes, cookies, and sausages using mini processing techniques [60]. Additionally, the high oil absorption capacity makes the flour suitable for enhancing flavor and mouthfeel [61]. Low oil absorption capacity is needed to produce fried products, so we do not absorb much oil while frying.

The swelling power is an indication of the absorption index of the granules during heating [6]. This study showed that the interactions of pretreatment and drying methods had a significant effect $(P<0.05)$ on the swelling power of anchote flour (Table 4). Both factors equally influence the swelling power of the sample. The value ranged from 9.39 to $12.60 \mathrm{~g} / \mathrm{g}$. Comparable results for anchote flour were indicated at $11.48 \mathrm{~g} / \mathrm{g}$ [17] and 9.36 to $12.58 \mathrm{~g} / \mathrm{g}$ [8], but slightly lower swelling power was reported for sweet potato at 6.30-9.59 [28].

The untreated anchote flour has significantly lower swelling power than the pretreated anchote flour. Regarding this study, blanching methods could increase the swelling power of anchote flour. This might be during blanching; there was the degradation of starch. The same trend was reported by Jangchud et al. [62]. The blanching method could increase the swelling power of sweet potato flour. Correspondingly, the anchote samples dried with the aid of oven drying had higher swelling power than the solar- and sun-drying methods. The swelling power increased as the temperature increased [63]. This is an indication that an increase in temperature weakened the starch granules by allowing interaction between the amylose (water-soluble fraction) molecules located in the bulk amorphous regions and the branched segment of amylopectin (water-insoluble fraction) in the crystalline regions [64].

The solubility index is related to the extent of leaching of amylose out of starch granules during swelling and is affected by intermolecular forces and the presence of surfactants and other related substances [65]. It provides 
TABLE 4: Functional properties of anchote flour as affected by pretreatments and drying methods.

\begin{tabular}{|c|c|c|c|c|c|c|}
\hline $\operatorname{Dr} * \operatorname{Prt}$ & $\begin{array}{c}\text { Water absorption } \\
(\mathrm{g} / \mathrm{g})\end{array}$ & $\begin{array}{l}\text { Oil absorption } \\
(\mathrm{ml} / \mathrm{g})\end{array}$ & $\begin{array}{l}\text { Swelling capacity } \\
(\mathrm{g} / \mathrm{g})\end{array}$ & $\begin{array}{c}\text { Solubility } \\
(\%)\end{array}$ & $\begin{array}{c}\text { Foaming } \\
\text { capacity }(\%)\end{array}$ & $\begin{array}{c}\text { Dispersibility } \\
(\%)\end{array}$ \\
\hline CS & $2.04 \pm 0.03^{\mathrm{e}}$ & $1.88 \pm 0.13^{\mathrm{ab}}$ & $9.39 \pm 0.62^{\mathrm{e}}$ & $38.80 \pm 0.73^{\mathrm{f}}$ & $4.03 \pm 0.07^{\mathrm{bc}}$ & $65.02 \pm 0.25^{\mathrm{bc}}$ \\
\hline CSo & $2.33 \pm 0.13^{\mathrm{d}}$ & $2.01 \pm 0.07^{\mathrm{a}}$ & $9.59 \pm 0.32^{\text {de }}$ & $40.97 \pm 0.61^{\mathrm{cd}}$ & $4.16 \pm 0.11^{\mathrm{ab}}$ & $64.45 \pm 0.48^{\mathrm{c}}$ \\
\hline $\mathrm{CO}$ & $2.38 \pm 0.07^{\mathrm{cd}}$ & $1.72 \pm 0.09^{c}$ & $9.61 \pm 0.52^{\text {de }}$ & $41.94 \pm 0.42^{\mathrm{b}}$ & $4.30 \pm 0.22^{\mathrm{a}}$ & $65.03 \pm 0.29^{b c}$ \\
\hline BS & $2.38 \pm 0.06^{\mathrm{cd}}$ & $1.92 \pm 0.05^{\mathrm{a}}$ & $9.86 \pm 0.9^{\circ} \mathrm{C}$ de & $40.58 \pm 0.10^{\mathrm{d}}$ & $2.50 \pm 0.07^{\mathrm{d}}$ & $64.50 \pm 0.6^{\circ} \mathrm{C}$ \\
\hline BSo & $2.46 \pm 0.04^{b c}$ & $1.74 \pm 0.18^{\mathrm{bc}}$ & $11.45 \pm 0.47^{\mathrm{b}}$ & $40.33 \pm 0.61^{\mathrm{de}}$ & $2.49 \pm 0.19^{\mathrm{d}}$ & $66.37 \pm 0.14^{\mathrm{a}}$ \\
\hline $\mathrm{BO}$ & $2.56 \pm 0.04^{\mathrm{ab}}$ & $1.71 \pm 0.1^{\circ} \mathrm{C}$ & $12.60 \pm 0.58^{\mathrm{a}}$ & $43.84 \pm 0.37^{\mathrm{a}}$ & $2.26 \pm 0.18^{\mathrm{e}}$ & $66.30 \pm 0.97^{\mathrm{a}}$ \\
\hline $\mathrm{KS}$ & $2.42 \pm 0.04^{\mathrm{cd}}$ & $1.94 \pm 0.01^{\mathrm{a}}$ & $9.46 \pm 0.88^{\mathrm{e}}$ & $39.64 \pm 0.36^{\mathrm{ef}}$ & $3.92 \pm 0.09^{c}$ & $64.54 \pm 0.20^{\mathrm{bc}}$ \\
\hline KSo & $2.58 \pm 0.07^{\mathrm{ab}}$ & $2.01 \pm 0.07^{\mathrm{a}}$ & $10.66 \pm 0.60^{\mathrm{bcd}}$ & $40.52 \pm 0.52^{\mathrm{de}}$ & $3.99 \pm 0.09^{b c}$ & $65.63 \pm 1.00^{\mathrm{ab}}$ \\
\hline $\mathrm{KO}$ & $2.66 \pm 0.05^{\mathrm{a}}$ & $1.93 \pm 0.01^{\mathrm{a}}$ & $10.84 \pm 0.34^{b c}$ & $41.61 \pm 0.48^{\mathrm{bc}}$ & $4.12 \pm 0.11^{\mathrm{ab}}$ & $65.52 \pm 0.20^{\mathrm{a}}$ \\
\hline LSD & 0.12 & 0.17 & 1.08 & 0.89 & 0.19 & 1.09 \\
\hline $\mathrm{CV}$ & 2.98 & 5.28 & 6.03 & 1.27 & 3.14 & 2.97 \\
\hline
\end{tabular}

Values are mean \pm standard deviation. Values in the same column followed by different letters are significantly different $(P<0.05)$. CS: control and sun-dried sample, CSo: control and solar-dried sample, CO: control and oven-dried sample, BS: blanching and sun-dried sample, BSo: blanching and solar-dried sample, BO: blanching and oven-dried sample, KS: potassium metabisulphite and sun-dried sample, KSo: potassium metabisulphite and solar-dried sample, KO: potassium metabisulphite and oven-dried sample, LSD: least significant difference, and CV: coefficient of variation.

evidence of the magnitude of the interaction between starch chains within amorphous and crystalline domains. The extent of this interaction is also influenced by the amylose to amylopectin ratio and by the characteristics of amylose/ amylopectin in terms of molecular weight/distribution, degree and length of branching, and conformation [66]. The solubility value was significantly $(P<0.05)$ affected by the pretreatment methods, drying methods, and their interaction (Table 4). Because of this, the anchote samples treated by blanching methods and dried in the oven had the highest solubility rating of $43.84 \%$ and the lowest value of $38.80 \%$ for control and sun-dried samples. Oven drying could increase the solubility of anchote flour. This might be because high temperature weakens the starch granules in flour, which leads to enhanced solubility. The rise in solubility with temperature may be due to the increasing mobility of the starch granules, which facilitated enhanced dispersion of starch molecules in water [67].

Foaming capacity (FC) is used to determine the ability of the flour to foam, which is dependent on the presence of the flexible protein molecules which decrease the surface tension of water [68]. The foaming capacity was significantly affected by pretreatment methods and the interaction between drying and pretreatment methods, but the drying methods could not significantly affect the foaming capacity of anchote flour as shown in Table 4. The untreated samples were dried in the oven at the highest sample rate, $4.30 \%$, and the blanched samples were dried in the oven at 2.26, the lowest foaming capacity, with a significant $(P<0.05)$ difference between the values.

Dispersibility is an index of the ease of reconstitution of flour into a fine-consistency paste during stirring [67]. The dispersibility was significantly $(P<0.05)$ affected by the pretreatment methods, drying methods, and their interaction (Table 4). However, both factors have a slight significant $(P<0.05)$ effect on the dispersibility values of anchote flour. The dispersibility of anchote flour ranged from 64.50 to $65.52 \%$. A comparable result was reported: the dispersibility of anchote flour was $67.33 \%$ [18], and dispersibility of yam was 27.83-72.17 [59]. The sun-dried anchote flour had the highest dispersibility value, which is significantly different from both the oven-dried and solar-dried versions. Also, the untreated samples had significantly lower dispersibility values than the potassium-metabisulphite-treated and blanched anchote flour samples.

\section{Conclusion and Recommendation}

The study has indicated that different pretreatment methods and drying methods affect the quality of flour produced, and hence the different flours produced from the processing method differ in quality. The solar-dried samples had more protein content and color retention than other drying methods. So, it has an advantage in the economic processing of food for malnutrition. The color acceptance of the anchote flour was noticed in an increment while treating the samples by the blanching method and chemical treatment. The functional properties affect the blanched flour. Flour produced by the blanching method and dried in the oven had the highest water absorption capacity, and this gave it a higher affinity to absorb water during production. However, the maturity of tubers and the size of sliced tubers (length and width) are not studied and their effects on physicochemical and functional properties are not clearly understood. Additionally, the effects of blanching, chemical treatment, and drying methods and the association between functional properties and macronutrients are not evaluated separately and are recommended for future study. Further study should be conducted on the effect of different pretreatment and drying techniques on the mineral and antioxidant content of anchote flour.

\section{Data Availability}

The datasets that support the findings of this study are available from the corresponding author upon reasonable request.

\section{Conflicts of Interest}

The authors declare that they have no conflicts of interest. 


\section{Authors' Contributions}

Abebe Desalegn and Gesessew Kibr contributed to the design of the study, the proposal writing, tools developing, data analysis, and paper drafting and revising and agreed to be accountable for all aspects of the work.

\section{Acknowledgments}

The researchers want to express gratitude to the staff in the Departments of Chemical Engineering, and Food and $\mathrm{Nu}-$ tritional Sciences of Wollega University. This work was supported by Wollega University.

\section{References}

[1] T. Bekele, K. Kassa, T. Mengistu, M. Debele, and Y. Melka, "Working with communities to address deforestation in the Wondo genet catchment area, Ethiopia: lessons learnt from participatory action research," Research Journal of Agriculture and Environmental Management, vol. 2, no. 12, pp. 448-456, 2013.

[2] Y. Yambo and T. Feyissa, "Micro-propagation of anchote [Coccinia Abyssinica (Lam.) Cogn.]: high calcium content tuber crop of Ethiopia," African Journal of Agricultural Research, vol. 8, no. 46, pp. 5915-5922, 2013.

[3] F. Habtamu, "Effect of traditional processing methods on nutritional composition and anti-nutritional factors of anchote (Coccinia Abyssinica (Lam.) Cogn) grown in western Ethiopia," MSc Thesis, Addis Ababa University, Addis Ababa, Ethiopia, 2011.

[4] O. B. Oyewole, "The powers at the roots: foods and its microbial allies," in UNAAB Inaugural Lecture Series, University of Agriculture, no. 15, p. 56, Abeokuta, Nigeria, 2002.

[5] F. A. Ayinde and R. R. Dinrifo, "Effect of storage and prestorage treatments on the quality of dried sweet potato slices," Annals of Agricultural Sciences, vol. 22, no. 1, pp. 16-20, 2001.

[6] R. O. Adeleke and J. O. Odedeji, "Functional properties of wheat and sweet potato flour blends," Pakistan Journal of Nutrition, vol. 9, no. 6, pp. 535-538, 2010.

[7] M. Ahmed, A. M. Sorifa, and J. B. Eun, "Effect of pretreatments and drying temperatures on sweet potato flour," International Journal of Food Science and Technology, vol. 45, no. 4, pp. 726-732, 2010.

[8] F. Habtamu, B. Fekadu, and D. Gullelat, "Effect of traditional processing methods on nutritional composition and antinutritional factors of anchote (Coccinia Abyssinica (lam.) Cogn) tubers grown in Western Ethiopia," Journal of Food Process Technology, vol. 4, no. 7, pp. 1-8, 2013.

[9] P. Piotr, "Effect of pre-drying treatment, drying, and rehydration on plant tissue properties: a review," International Journal of Food Properties, vol. 1, no. 1, pp. 1-22, 1998.

[10] J. M. Babajide, A. O. Obadina, O. B. Oyewole, and L. N. Ugbaka, "Microbial quality of dry yam "gbodo" parboiled without adjuncts," African Journal of Biotechnology, vol. 5, pp. 278-281, 2006.

[11] E. Buckman, W. Plahar, I. Oduro, and E. Carey, "Effects of sodium metabisulphite and blanching pretreatments on the quality characteristics of yam bean (Pachyrhizus erosus) flour," British Journal of Applied Science \& Technology, vol. 6, no. 2, pp. 138-144, 2015.

[12] G. O. Ogunlakin, M. O. Oke, G. O. Babarinde, and D. G. Olatunbosu, "Effect of drying methods on proximate composition and physico-chemical properties of Cocoyam flour," American Journal of Food Technology, vol. 7, no. 4, pp. 245-250, 2012.

[13] J. Tang and T. Yang, "Dehydrated vegetables: principles and systems," in Handbook of Vegetable Preservation and Processing, Y. H. Hui, S. Chazala, D. M. Graham, K. D. Murrell, and W. K. k. Nip, Eds., pp. 335-372, Marcel Dekker, New York, NY, USA, 2004.

[14] H. Kocabiyık and B. S. Demirturk, "Infrared radiation drying of mint leaves," Tekirdağ Ziraat Fakultesi Dergisi, vol. 5, no. 3, pp. 239-246, 2008.

[15] C. Ertekin and O. Yaldiz, "Drying of eggplant and selection of a suitable thin layer drying model," Journal of Food Engineering, vol. 63, no. 3, pp. 349-359, 2004.

[16] H. Demelash, "Quality analysis of bread produced from blendes of wheat (Triticumaestivum L.) and Anchote (Coccinia Abyssinica L.)," Journal of Science, Technology and Arts Research, vol. 5, no. 1, pp. 61-68, 2016.

[17] A. D. Melese, S. Abera, and D. H. Mitiku, "Investigation of wheat - anchote (Coccinia Abyssinica (Lam.)) composite flours and baking temperature for cookies production," Food Research, vol. 5, no. 1, pp. 252-265, 2021.

[18] A. M. Bikila, Y. Tola, T. B. Esho, and S. F. Forsido, "Effect of predrying treatment and drying temperature on proximate composition, mineral contents, and thermophysical properties of anchote (Coccinia abyssinica (Lam.) Cogn.) flour," Food Science and Nutrition, vol. 8, no. 10, pp. 5532-5544, 2020.

[19] AOAC, Official Methods of Analysis, Association of Analytical, Washington, DC, USA, 17 edition, 2003.

[20] S. Giambi and D. Bekebian, "Proximate composition and functional properties of raw and processed full-fat fluted pumpkin (telfairiaoccidentalis) seed flour," Journal of the Science of Food and Agriculture, vol. 59, pp. 321-325, 1992.

[21] J. Shumaila, I. Syed, and D. C. Saxena, "Effect of physical properties on the flowability of commercial rice flour/powder for effective bulk handling," International Journal of Computer Applications, pp. 0975-8887, 2015.

[22] D. R. Palatnik, M. V. Ostermann Porcel, U. González, N. Zaritzky, and M. E. Campderrós, "Recovery of Caprine whey protein and its application in a food protein formulation," Lebensmittel-Wissenschaft und -Technologie- Food Science and Technology, vol. 63, no. 1, pp. 331-338, 2015.

[23] K. Zhu, P. J. Kanu, I. P. Claver, K. Zhu, H. Qian, and H. Zhou, "A method for evaluating Hunter whiteness of mixed powders," Advanced Powder Technology, vol. 20, no. 2, pp. 123-126, 2009.

[24] B. W. Abbey and G. O. Ibeh, "Functional properties of raw and heat processed cowpea," Advance Journal of Food Science and Technology, vol. 2, no. 1, pp. 41-44, 1988.

[25] H. W. Leach, L. D. Cowen, and T. J. Schoch, "Structure of the starch granules, in swelling and solubility patterns of various starches," Cereal Chemistry, vol. 36, pp. 534-544, 1959.

[26] J. T. Lawhon, C. N. Cater, and K. F. Mattil, "A comparative study of the whipping potential of an extract from several oil seed flours," Cereal Science Today, vol. 17, no. 4, pp. 240-244, 1972.

[27] J. Gbemisola, O. Lateef, A. Abdul, K. Sarafadeen, and S. Paul, "Effect of drying methods on the chemical composition, color, functional, and pasting properties of plantain (Musa Paradisiacal) flour," Journal of Food Technology, Biotechnology, and Nutrition, vol. 13, no. 1-2, pp. 38-43, 2018.

[28] K. Ngoma, M. E. Mashau, and H. Silungwe, "Physicochemical and functional properties of chemically pretreated $\mathrm{Ndou}$ sweet 
potato flour," International Journal of Food Science, vol. 2019, Article ID 4158213, 2019.

[29] F. Habtamu, "Effects of boiling methods on anti-nutritional factors of Anchote (Coccinia Abyssinica (lam.)Cogn) tubers grown in Western Ethiopia," Food Science and Quality Management, vol. 27, pp. 39-40, 2014.

[30] A. Yenenesh, R. Nigusse, D. Gulelat, M. Ali, and M. Adey, "Amino acid profile and protein quality in tuber and leaf of Coccnia Abyssinica (Lam.) (Cogn.) accessions of Ethiopia," Food Science and Nutrition, vol. 5, no. 3, pp. 722-729, 2016.

[31] O. Malomo, O. Jimoh, O. Adekoyeni, E. Soyebi, and A. Alamu, Effect of Blanching and Unblanching on Rheological Properties of Sweet-Potato Bread, College of Food Sciences, Bells University of Technology, Academic Research International, Ota Ogun State, Nigeria, 2013.

[32] A. Olapade and A. Adeyemo, "Evaluation of cookies produced from blends of wheat, cassava, and cowpea flour," International Journal of Food Studies, vol. 3, pp. 175-185, 2014.

[33] H. Fana, A. Shimelis, and F. Abrehet, "Effects of pre-treatments and drying methods on chemical composition, microbial and sensory quality of orange-fleshed sweet potato flour and porridge," American Journal of Food Science and Technology, vol. 3, no. 3, pp. 82-88, 2015.

[34] W. J. Dahl and M. L. Stewart, "Position of the academy of nutrition and dietetics: health implications of dietary fiber," Journal of the Academy of Nutrition and Dietetics, vol. 115, no. 11, pp. 1861-1870, 2015.

[35] G. Gizachew, B. Geremew, and A. Solomon, "Effect of cassava (Manihotesculenta Crantz) variety, drying method, and blending ratio on the proximate composition and sensory properties of cassava-wheat composite bread," European Journal of Food Science and Technology, vol. 3, no. 4, pp. 41-54, 2015.

[36] O. O. Ganiyat, O. H. Folake, A. I. Michael, and T. Keith, "Quality attributes of sweet potato flour as influenced by variety, pretreatment, and drying method," Food Science and Nutrition, vol. 4, no. 4, pp. 623-635, 2016.

[37] F. L. Kolawole, M. A. Balogun, F. D. Usman, and S. A. Akeem, "Effect of drying methods on the chemical and functional properties of potato (Solanumtu Berosum) and sweet potato (Ipomoea Batatas) varieties," Nigerian Journal of Agriculture, Food and Environment, vol. 12, no. 4, pp. 151-156, 2016.

[38] J. O. Odadeji and W. A. Oyeleke, "Comparative studies on functional properties of whole and dehulled cowpea seed flour (Vignaunguiculata)," Pakistan Journal of Nutrition, vol. 10, no. 9, pp. 899-902, 2011.

[39] U.S. Government Publishing Office, United States Department of Agriculture and United State Standards for Rice, Federal Grain Inspection Service, U.S. Government Publishing Office, Washington, DC, USA, 2009.

[40] C. Balagopalan, G. Padmaja, S. K. Nanda, and S. N. Moorthy, Cassava in Food, Feed, and Industry, CRC Press, Boca Raton, FL, USA, 1988.

[41] S. Chandra and S. Singh, "Assessment of functional properties of different flours," African Journal of Agricultural Research, vol. 8, no. 38, pp. 4849-4852, 2013.

[42] G. J. Fadimu, L. O. Sanni, A. R. Adebowale et al., "Effect of drying methods on the chemical composition, color, functional, and pasting properties of plantain (Musa Paradisiacal) flour," Croatian Journal of Food Technology, Biotechnology and Nutrition, vol. 13, no. 1-2, pp. 38-43, 2018.

[43] A. B. Adepeju, S. O. Gbadamosi, A. H. Adeniran, and T. O. Omobuwajo, "Functional and pasting characteristics of breadfruit (Artocarpusaltilis) flours," African Journal of Food Science, vol. 5, pp. 529-535, 2011.

[44] T. N. Fagbemi and O. Olaofe, "Functional properties of raw and precooked taro and tanninflours," in Proceedings of the 22nd Annual Conference of Nigerian, pp. 23-26, Institute of Food Science and Technology, Abeokuta, Nigeria, November 1998.

[45] D. Abebe and H. Demelash, "Particle size distribution, rheological and pasting properties of wheat, anchote and their composite flour," International Journal of Food and Nutrition Sciences, vol. 5, no. 1, pp. 131-143, 2020.

[46] B. Evelyn, P. Wisdom, O. Ibok, and C. Edward, "Effects of sodium metabisulphite and blanching pretreatments on the quality characteristics of Yam Bean (Pachyrhizuserosus) flour," British Journal of Applied Science and Technology, vol. 6, no. 2, pp. 138-144, 2015.

[47] Y. Li and M. Zhao, "Simple methods for rapid determination of sulfite in food products," Food Control, vol. 17, no. 12, pp. 975-980, 2006.

[48] M. A. Ali, Y. A. Yusof, N. L. Chin, and M. Ibrahim, "Effect of different drying treatments on color quality and ascorbic acid concentration of guava fruit," International Food Research Journal, vol. 23, pp. 155-161, 2016.

[49] F. Salehi and M. Kashaninejad, "Modeling of moisture loss kinetics and color changes in the surface of lemon slice during the combined infrared-vacuum drying," Information processing in Agriculture, vol. 5, no. 4, pp. 516-523, 2018.

[50] R. F. d. Nascimento and M. H. G. Canteri, "Effect of blanching on physicochemical characteristics of potato flour," Horticultura Brasileira, vol. 36, no. 4, pp. 461-465, 2018.

[51] M. K. Krokida, V. T. Karathanos, and Z. B. Maroulis, "Effect of osmotic dehydration on color and sorption characteristics of apple and banana," Drying Technology. An International Journal, vol. 18, no. 4-5, pp. 37-41, 2000.

[52] C. Tortoe, P. T. Akonor, K. Koch, C. Menzel, and K. Adofo, "Physicochemical and functional properties of flour from twelve varieties of Ghanaian sweet potatoes," International Food Research Journal, vol. 24, no. 6, pp. 2549-2556, 2017.

[53] P. H. Hung and N. Morita, "Dough properties and bread quality of bread flours supplemented with cross-linked corn starch," Food Research International, vol. 37, pp. 461-467, 2003.

[54] R. M. O. Kayode, O. J. Buhari, L. O. Ajibola, S. A. Oyeyinka, D. O. Opaleke, and S. A. Akeem, "Physicochemical properties of processed aerial yam (Dioscorea bulbifera) and sensory properties of paste (Amala) prepared with Cassava flour," Journal of Agricultural Sciences, vol. 12, no. 2, pp. 84-94, 2017.

[55] A. A. Olubunmi, I. O. Abraham, L. A. Mojirade, B. Afolake, and O. E. Kehinde, "Development, evaluation, and sensory quality of orange fleshed sweet potato (Ipomoea Batatas Lam) extruded pasta products," Croatian Journal of Food Technology, Biotechnology and Nutrition, vol. 12, no. 1-2, pp. 8389, 2017.

[56] B. D. Bello and C. N. Ekeh, "Proximate composition and functional properties of wheat, sweet potato, and hamburger bean flour blends global advertise of research," Journal of Food Science and Technology, vol. 3, no. 4, pp. 118-124, 2014.

[57] E. Eriksson, K. Koch, C. Tortoe, P. T. Akonor, and E. Baidoo, "Physicochemical, functional and pasting characteristics of three varieties of cassava in wheat composite flours," British Journal of Applied Science and Technology, vol. 4, no. 11, pp. 1609-1621, 2014.

[58] E. C. Ndie, C. V. Nnamani, and H. O. Oselebe, "Some physicochemical characteristics of defatted flours derived 
from african walnut (Tetracarpidium conoforum): an underutilized legume," Pakistan Journal of Nutrition, vol. 9, no. 9, pp. 909-911, 2010.

[59] A. W. Bashirat, R. A. Abdul, and A. Adebowale, "Effect of species, pretreatments, and drying methods on the functional and pasting properties of high-quality yam flour," Food Science and Nutrition, vol. 4, no. 1, pp. 50-58, 2016.

[60] J. A. Adejuyitan, E. T. Otunola, A. Emmanuel, and I. F. Bolarinwa, "Some physicochemical properties of flour obtained from fermentation of tigernut (Cyperus esculentus) sourced from a market in ogbomoso, Nigeria," African Journal of Food Science, vol. 3, no. 2, pp. 51-55, 2009.

[61] F. Appiah, J. Y. Asibuo, and P. Kumah, "Physicochemical and functional properties of bean flours of three cowpeas (Vignaunguiculata L. Walp) varieties in Ghana," African Journal of Food Science, vol. 5, no. 2, pp. 100-104, 2011.

[62] K. Jangchud, Y. Phimolsiripol, and V. Haruthaithanasan, "Physicochemical properties of sweet potato flour and starch as affected by blanching and processing," Starch-Stärke, vol. 55, no. 6, pp. 258-264, 2003.

[63] A. Ramesh Yadav, M. Guha, R. N. Tharanathan, and R. S. Ramteke, "Changes in characteristics of sweet potato flour prepared by different drying techniques," LebensmittelWissenschaft und-Technologie-Food Science and Technology, vol. 39, no. 1, pp. 20-26, 2006.

[64] R. Hoover and H. Manuel, "Effect of heat-moisture treatment on the structure and physicochemical properties of legume starches," Food Research International, vol. 29, no. 8, pp. 731-750, 1996.

[65] S. N. Moorthy, "Physicochemical and functional properties of tropical tuber starches: a review," Starch-Stärke, vol. 54, no. 12 , pp. 559-592, 2002.

[66] R. Hoover, "Composition, molecular structure, and physicochemical properties of tuber and root starches: a review," Carbohydrate Polymers, vol. 45, no. 3, pp. 253-267, 2001.

[67] Y. Adebowale, I. Adeyemi, and A. Oshodi, "Functional and physicochemical properties of flours of six mucuna species," African Journal of Biotechnology, vol. 4, no. 12, pp. 1461-1468, 2005.

[68] S. M. Asif-Ul-Alam, M. Z. Islam, M. M. Hoque, and K. Monalisa, "Effects of drying on the physicochemical and functional properties of green banana (Musa sapientum) flour and development of baked product," American Journal of Food Science and Technology, vol. 2, no. 4, pp. 128-133, 2014. 